MEDIA ILMIAH TEKNIK SIPIL

Volume 5 Nomor 2 Juni 2017

Hal. 89-93

\title{
KUAT TEKAN BEBAS TANAH LEMPUNG DISTABILISASI PASIR DAN SEMEN UNTUK PERKERASAN JALAN RAYA
}

\author{
Anwar Muda \\ Balai Besar Pelaksanaan Jalan Nasional II \\ Direktorat Jenderal Bina Marga
}

\begin{abstract}
ABSTRAK
Penelitian ini bertujuan untuk mengetahui kuat tekan bebas tanah lempung distabilisasi pasir dan semen untuk perkerasan jalan.

Hasil penelitian menunjukkan, bahwa stabilisasi pasir sebesar $12 \%$ dengan semen $2 \%$, nilai UCS naik menjadi $0.49 \mathrm{~kg} / \mathrm{cm}^{2}$ dari kondisi awal $0.41 \mathrm{~kg} / \mathrm{cm}^{2}$. Kemudian, penambahan semen $4 \%$, nilai UCS juga mengalami kenaikan sebesar $4.44 \mathrm{~kg} / \mathrm{cm}^{2}$. Pada penambahan semen sebesar $6 \%$, nilai UCS mengalami kenaikan hingga 5.29 $\mathrm{kg} / \mathrm{cm}^{2}$ dan penambahan semen sebesar $8 \%$, nilai UCS naik menjadi $7.33 \mathrm{~kg} / \mathrm{cm}^{2}$ serta penambahan semen $10 \%$, nilai UCS mengalami kenaikan menjadi $9.06 \mathrm{~kg} / \mathrm{cm}^{2}$. Sehingga, dengan penambahan pasir sebesar $12 \%$ dan semen optimum $8 \%$ memenuhi syarat teknis lapis pondasi bawah jalan raya karena nilai UCS hasil $7.33 \mathrm{~kg} / \mathrm{cm}^{2}>6$ $\mathrm{kg} / \mathrm{cm}^{2}$.
\end{abstract}

Kata kunci : kuat tekan bebas, tanah lempung, stabilisasi, pasir, semen 


\section{PENDAHULUAN}

Stabilisasi tanah adalah pencampuran tanah dengan bahan tertentu, guna memperbaiki sifat-sifat teknis tanah atau dapat pula, stabilisasi tanah adalah usaha untuk merubah atau memperbaiki sifat-sifat teknis tanah agar memenuhi syarat teknis tertentu. Sifatsifat teknis tanah seperti kuat tekan bebas (UCS) tanah lempung umumnya sangat rendah. Seperti tanah lempung Ciawi (UCS) $0,65 \quad \mathrm{~kg} / \mathrm{cm}^{2}$ (Wahjuningsih, 1997), tanah lempung Indramayu (UCS) 0,195 kg/ $\mathrm{cm}^{2}$ (Sudirja, 2008) dan UCS tanah lempung Bukit Rawi 0,43 kg/ $\mathrm{cm}^{2}$ (Muda, 2011). Namun jika dilihat besaran kuat tekan bebas tanah tersebut maka tanah tersebut termasuk lempung sangat lunak sampai sedang dengan nilai UCS 0 $1,00 \mathrm{~kg} / \mathrm{cm}^{2}$ (Hardiyatmo, 2006).

Permasalahan rendahnya kuat tekan bebas (UCS) tanah lempung Bukit Rawi disebabkan tanah ini mempunyai Indeks plastisitas (PI) 16,81\% dengan penilaian umum sebagai tanah dasar sedang sampai buruk

Melihat permasalahan di atas, pada penelitian ini akan dilakukan peningkatan kuat tekannya (ucs) distabilisasi pasir dan semen. Campuran pasir direncanakan $12 \%$ terhadap berat isi kering lempung. Kemudian, pembuatan campuran semen dengan lempung dan pasir yang sudah tercampur pada kondisi optimum. Campuran semen direncanakan 2, 4, 6, 8 dan $10 \%$ terhadap berat isi kering campuran lempung dan pasir. Pada campuran tersebut dilakukan pengujian UCS untuk subgrade jalan raya.

\section{KAJIAN PUSTAKA YANG RELEVAN}

\section{Stabilisasi pasir}

Stabilisasi menggunakan campuran pasir bertujuan untuk mengukur perubahan indeks plastisitas (PI). Hicks, 2002 (dalam Hardiyatmo, 2010) menyebutkan, tanah berbutir halus seperti lempung jika distabilisasi dengan semen sebaiknya tanah tersebut bila uji saringan No. $200 \geq 25 \%$ maka indeks plastisitas $(\mathrm{PI}) \leq 10 \%$. Jika tanah tersebut bilia uji saringan No. $200<25 \%$ maka indeks plastisitas (PI) $\leq 10 \%$ atau $\mathrm{PI} \geq 10 \%$ atau $\mathrm{PI} \leq 6$ (PI $x$ persen lolos saringan No. $200 \leq 60$ seperti pada Tabel 2.1.

Tabel 2.1 Petunjuk awal untuk pemilihan metode stabilisasi

\begin{tabular}{|c|c|c|c|c|c|c|}
\hline $\begin{array}{l}\text { Material lolos } \\
\text { saringan No.200 }\end{array}$ & \multicolumn{3}{|c|}{$\begin{array}{l}>25 \% \text { lolos saringan } \\
\text { No. } 200(0,075 \mathrm{~mm})\end{array}$} & \multicolumn{3}{|c|}{$\begin{array}{l}\angle 25 \% \text { lolos saringan } \\
\text { No. } 200(0,075 \mathrm{~mm})\end{array}$} \\
\hline $\begin{array}{c}\text { Indeks plastisitas } \\
\text { PI }(\%)\end{array}$ & $\leq 10$ & $\begin{array}{c}10- \\
20\end{array}$ & $\geq 20$ & $\begin{array}{c}\leq 6(\mathrm{PI}) \mathrm{x} \\
\text { persen } \\
\text { lolos } \\
\text { saringan } \\
\text { No. 200 } \\
\leq 60\end{array}$ & $\leq 10$ & $\geq 10$ \\
\hline \multicolumn{7}{|l|}{ Bentuk stabilisasi } \\
\hline $\begin{array}{l}\text { Semen dan } \\
\text { campuran } \\
\text { pengikat }\end{array}$ & Cocok & Ragu & $\begin{array}{l}\text { Tidak } \\
\text { cocok }\end{array}$ & Cocok & Cocok & Cocok \\
\hline Kapur & Ragu & Cocok & $\begin{array}{l}\text { Tidak } \\
\text { cocok }\end{array}$ & $\begin{array}{l}\text { Tidak } \\
\text { cocok } \\
\end{array}$ & Ragu & Cocok \\
\hline Aspal (bitumen) & Ragu & Ragu & $\begin{array}{l}\text { Tidak } \\
\text { cocok }\end{array}$ & Cocok & Cocok & Ragu \\
\hline $\begin{array}{l}\text { Aspal/semen } \\
\text { dicampur }\end{array}$ & Ragu & Ragu & $\begin{array}{l}\text { Tidak } \\
\text { cocok }\end{array}$ & Cocok & Cocok & Ragu \\
\hline Granular & Cocok & $\begin{array}{l}\text { Tidak } \\
\text { cocok }\end{array}$ & $\begin{array}{l}\text { Tidak } \\
\text { cocok }\end{array}$ & Cocok & Cocok & Ragu \\
\hline $\begin{array}{l}\text { Lain-lain } \\
\text { campuran }\end{array}$ & $\begin{array}{l}\text { Tak } \\
\text { cocok }\end{array}$ & Cocok & Cocok & Ragu & Ragu & Cocok \\
\hline
\end{tabular}

Sumber : Hicks, 2002 (dalam Hardiyatmo, 2010)

\section{Stabilisasi semen}

Kriteria stabilisasi tanah menggunakan semen menurut maksud dan penggunaannya yang diusulkan oleh Ingels dan Metcalf (1972) dalam Tabel 2.2. dan kriteria kekuatan stabilisasi tanah semen untuk Lapis Pondasi Bawah (LPB) dan Lapis Pondasi Atas (LPA) oleh Ditjen Bina Marga yang didasarkan pada SNI 
Kuat Tekan Bebas Tanah Lempung..., Anwar Muda

03-3438-1994 (dalam Hardiyatmo, 2010) dalam

Tabel 2.3 berikut.

Tabel 2.2 Kriteria stabilisasi tanah menggunakan semen

\begin{tabular}{|c|c|c|c|c|c|}
\hline \multirow[t]{2}{*}{ Puipose } & \multicolumn{2}{|c|}{ U.C.S."II } & \multirow[t]{2}{*}{$C B R_{1}|2|$} & \multirow{2}{*}{ Swell } & \multirow{2}{*}{$\frac{\begin{array}{c}\text { Loss in } \\
\text { well/dry lest }\end{array}}{\text { percent }}$} \\
\hline & $\mathrm{kg} / \mathrm{cm}^{2}$ & $\left(\mathrm{~b} b / / \mathrm{in}{ }^{2}\right)$ & & & \\
\hline Road sub-base, Iormation & & & & & \\
\hline $\begin{array}{l}\text { backill lor trenches elc. } \\
\text { Road sub-base, base tor }\end{array}$ & $3.5 \cdot 10.5$ & $(50.150)$ & 20.80 & 2 & 1 \\
\hline $\begin{array}{l}\text { light trattic } \\
\text { Base lor heavy trattic }\end{array}$ & 7.14 & $(100 \cdot 200)$ & 50.150 & 2 & 10 \\
\hline $\begin{array}{l}\text { Building blocks } \\
\text { Embankment protection } \\
\text { Floodways (too strong tor } \\
\text { general use under thin }\end{array}$ & 14.56 & $(200-800)$ & $200 \cdot 600$ & 2 & 14 \\
\hline surfacings) & $>56$ & (800) & 600 & 2 & 14 \\
\hline
\end{tabular}

III U.C.S. cured seven days al constant moisture content. The loss ol strength on soaking should not be more than 20 per cent.

(2) C.B.R, - Soaked lour days.

13) Ourability lest apporopiriate only where moisture penetiation is likely to occur. Higher cement conlents may be required to meel this crilerion.

II) Lower strengiths may be adequate lor well-drained areas in the tropics.

Sumber : Ingels dan Metcalf (1972)

Tabel 2.3 Kriteria kekuatan stabilisasi tanah semen

\begin{tabular}{|c|c|c|}
\hline Uraian & $\begin{array}{c}\text { Kuat tekan bebas } \\
\left(\mathrm{kg} / \mathrm{cm}^{2}\right)\end{array}$ & CBR (\%) \\
\hline \hline $\begin{array}{c}\text { Lapis Pondasi Atas (LPA) } \\
7 \text { hari }\end{array}$ & 22 & 80 \\
\hline $\begin{array}{c}\text { Lapis Pondasi Bawah (LP) } \\
7 \text { hari }\end{array}$ & 6 & 20 \\
\hline
\end{tabular}

Sumber : Hardiyatmo (2010)

Muda (2011), melakukan penelitian tesis dengan judul Stabilisasi Tanah Lempung Bukit Rawi Menggunakan Pasir dan Semen. Penelitian dilatarbelakangi dengan mengangkat permasalahan rendahnya daya dukung tanah. Dari uji analisa saringan, bahwa tanah ini lolos saringan no. 200 sebesar $71.42 \%>50 \%$, sehingga tanah ini termasuk kelompok tanah berbutir halus. Kemudian dari uji daya dukung tanah, bahwa tanah ini memiliki nilai kuat tekan bebas $0.41 \mathrm{~kg} / \mathrm{cm}^{2}$ sehingga tanah ini memiliki konsistensi lempung lunak dan memiliki daya dukung sangat buruk untuk perkerasan jalan raya.

Arif (2006), melakukan penelitian Stabilisasi Tanah Liat Lunak dengan Garam dan Portland Cement (PC), menyatakan, praktis untuk tanah liat lunak asli tak dapat dilakukan karena benda uji tak bisa dibuat. Namun dengan penambahan garam dan semen kondisi tanah menjadi lebih baik sehingga benda uji bisa di buat.

Hasil pengujian menunjukkan pengaruh kadar garam terhadap nilai UCS masing-masing untuk curing 7, 14 dan 28 hari untuk kadar semen 16\% pada curing 7 hari, UCS meningkat dengan naiknya kadar garam, tapi untuk curing 14 dan 28 hari justru menurun. Untuk kadar PC 13\% nilai UCS berkurang dengan bertambahnya kadar garam pada curing 7, 14 dan 28 hari, disini jelas kuatnya pengaruh curing terhadap hubungan antara UCS dan kadar garam.

\section{METODE PENELITIAN}

Penelitian dillakukan di laboratorium Mekanika Tanah Universitas Muhammadiyah Palangkaraya Jl. RTA Milono Km 1,5 Palangka Raya. Metode penelitian ini mengacu pada diagram alir seperti pada Gambar 3.2 berikut. 


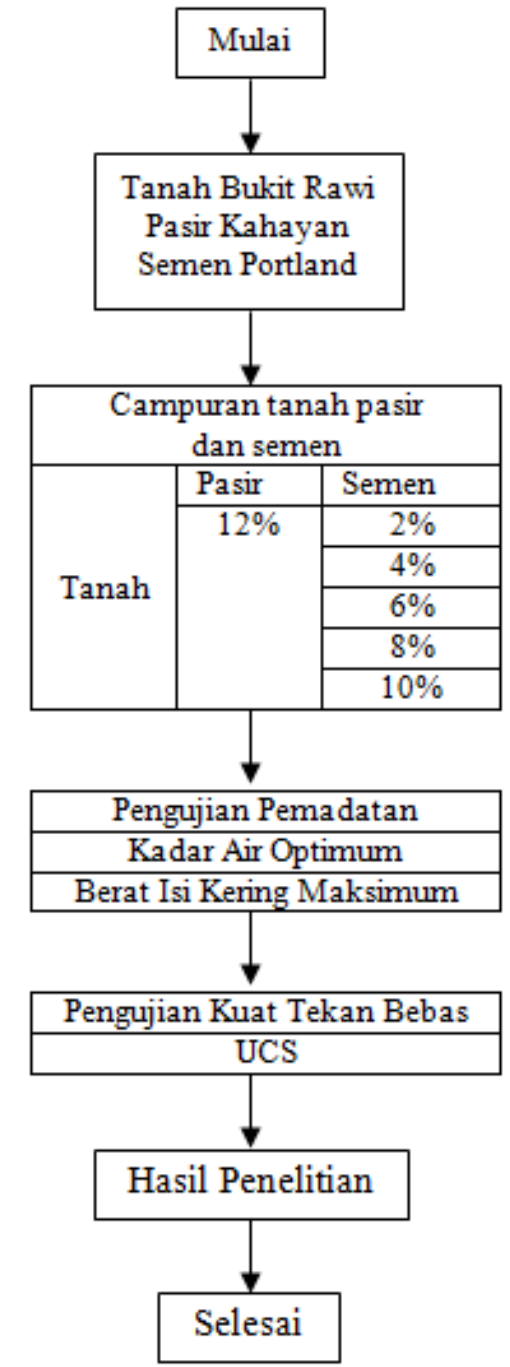

Gambar 3.2 Diagram Alir Penelitian

\section{HASIL DAN PEMBAHASAN}

\section{Karakteristik tanah asli}

Adapun karakteristik tanah asli Bukit Rawi dapat dilihat pada Tabel 4.1 berikut.

Tabel 4.1 Karakteristik tanah asli Bukit Rawi

\begin{tabular}{|l|c|l|}
\hline \multicolumn{1}{|c|}{ Tipe Pengujian } & Satuan & \multicolumn{1}{c|}{ Hasil } \\
\hline Berat Jenis & & 2.645 \\
\hline Berat isi Kering Maks & $\mathrm{g} / \mathrm{cm}^{3}$ & 1.415 \\
\hline Kadar Air Optimum & $\%$ & 26.60 \\
\hline UCS & $\mathrm{kg} / \mathrm{cm}^{2}$ & 0.41 \\
\hline
\end{tabular}

Berdasarkan Tabel 4.1 di atas, menurut AASHTO (dalam Hardiyatmo, 2006) bahwa tanah ini termasuk lempung organik karena Gs hasil uji 2,645 berada pada interval 2,58 - 2,65 (Hardiyatmo, 2006). Sedangkan dari kepadatan tanah diperoleh 1,415 $\mathrm{gr} / \mathrm{cm}^{3}$ pada kadar optimum $26,60 \%$. Kemudian pada uji UCS diperoleh $0.41 \mathrm{~kg} / \mathrm{cm}^{2}$. Menurut Bina Marga (dalam Hardiyatmo, 2010), bahwa tanah ini termasuk UCS dengan konsistensi tanah lunak dan memiliki yang untuk subgrade jalan raya

Karakteristik tanah asli setelah distabilisasi pasir dan semen

Adapun karakteristik tanah asli Bukit Rawi setelah penambahan pasir dan semen dapat dilihat pada Tabel 4.2 dan Gambar 4.1

Tabel 4.2 Karakteristik tanah lempung setelah distabilisasi campuran pasir dan semen

\begin{tabular}{|c|c|c|}
\hline $\begin{array}{c}\text { Campuran } \\
\text { Pasir } \\
(\%)\end{array}$ & $\begin{array}{c}\text { Campuran } \\
\text { Semen } \\
(\%)\end{array}$ & $\begin{array}{c}\text { UCS } \\
\left(\mathbf{k g} / \mathbf{c m}^{2}\right)\end{array}$ \\
\hline \multirow{4}{*}{12} & 2 & 0.49 \\
\cline { 2 - 3 } & 4 & 4.44 \\
\cline { 2 - 3 } & 6 & 5.29 \\
\cline { 2 - 3 } & 8 & 7.33 \\
\cline { 2 - 3 } & 10 & 9.06 \\
\hline
\end{tabular}

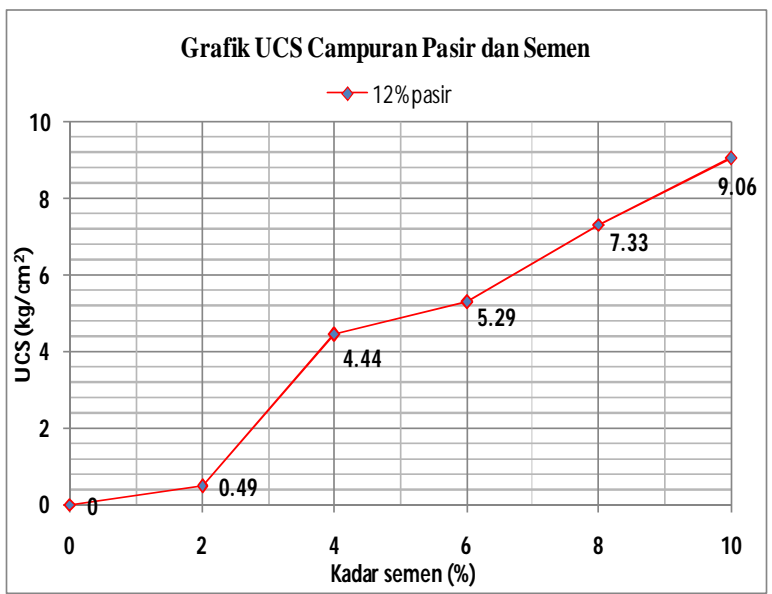

Gambar 4.1 Grafik UCS Campuran Pasir dan Semen 
Kuat Tekan Bebas Tanah Lempung..., Anwar Muda

Pada Tabel 4.2 atau Gambar 4.1 terlihat bahwa nilai UCS naik seiring bertambahnya campuran pasir dan semen. Kemudian pada saat stabilisasi tanah lempung dengan campuran $12 \%$ pasir dan $10 \%$ semen nilai diperoleh nilai UCS sebesar $9.06 \mathrm{~kg} / \mathrm{cm}^{2}$. Sehingga, stabilisasi tanah lempung bukit Rawi memenuhi syarat untuk Lapis Pondasi Bawah Jalan Raya karena nilai UCS $9.06 \mathrm{~kg} / \mathrm{cm}^{2}>$ UCS $6 \mathrm{~kg} / \mathrm{cm}^{2}$ Naiknya nilai UCS ini disebabkan bahwa penambahan semen menjadi media perekat bila bereaksi dengan air. Media perekat ini kemudian memadat dan membentuk massa yang keras sehingga lebih kuat menahan beban.

\section{DAFTAR PUSTAKA}

Hardiyatmo, H.C (2006), Mekanika Tanah 1, Edisi Keempat, Gajah Mada University Press, Yogyakarta

Ingles, O.G, dan Metcalf, J.B, (1972), Soil stabilization Principle and Practice, Butterworths Pty. Limited, Melbourne.

Moerdika, O.V, (2002), Stabilisasi Tanah Laterit dari Lampung Untuk Digunakan Sebagai Bahan Lapis Pondasi Perkerasan, Institut Teknologi Bandung.

Punmia, B.C (1973), Soil Mechanics and Foundation, Laxmi Publication (P), Ltd, New Delhi.

Soedarmo, G.D dan Purnomo, J.D (1997), Mekanika

Tanah 1, Kanisius, Jogjakarta

Sujianto,A.T (2007), Stabilisasi Tanah Lempung Ekspansif Dengan Garam Dapur ( $\mathrm{NaCl}$ ) (Jurnal Teknik Sipil Volume 8, No.1, 2007)

Sukirman, S (1999), Perkerasan Lentur Jalan Raya, Nova, Bandung

Wesley, L.D, (1977), Mekanika Tanah, Cetakan ke VI, Badan Penerbit Pekerjaan Umum, Jakarta.
Muda, A (2011), Stabilisasi Tanah Lempung Bukit Rawi Menggunakan Pasir dan Semen, Program Studi Magister Teknik Sipil Universitas Lambung Mangkurat, Banjarmasin 